\title{
O DEEMOS VAI À GUERRA: TRADUÇÃO E COMENTÁRIO DOS FR. II E III FGE ATRIBUÍDOS A SIMÔNIDES DE CEOS
}

\author{
ROBERT DE BROSE*
}

Universidade Federal do Ceará

\begin{abstract}
Resumo. No presente artigo irei traduzir e comentar os fragmentos II e III FGE, atribuídos a Simônides de Ceos. A partir da análise do texto, do contexto histórico e das evidências textuais, irei argumentar que os dois epigramas referem-se a um mesmo evento, a saber, a Batalha da Calcídia de c.507/6 a.C., sendo que o II FGE refere-se aos atenienses mortos em combate e, provavelmente, fazia parte de uma monumento colocado in situ, no local da vitória, ou em um mnèma na cidade de Atenas, ao passo que o outro epigrama, que apresenta uma continuidade temática com o II FGE, fazia parte de um monumento dedicado à vitória sobre os beócios na batalha supracitada.
\end{abstract}

Palavras-chave. Simônides de Ceos; epigrama; II FGE; III FGE.

D.O.I. 10.11606/issn.2358-3150.v17i2p3-30

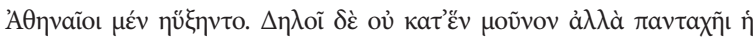

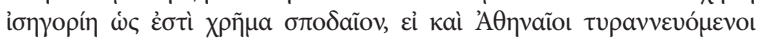

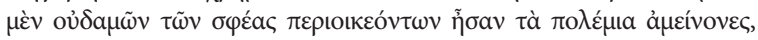

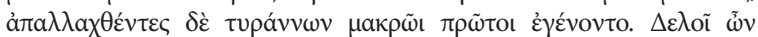

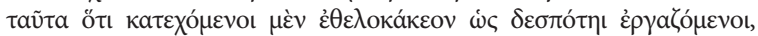

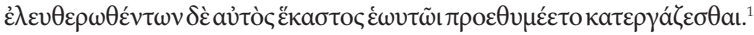

— Heródoto, 5.78
\end{abstract}

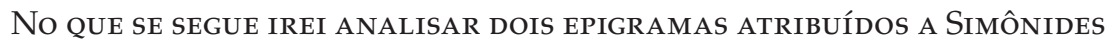
de Ceos tanto pelas antologias antigas quanto pela maioria dos comentadores modernos. A razão pela qual resolvi reuni-los neste artigo é a de que acredito que ambos referem-se a um mesmo evento, a saber, a Batalha da Calcídia (c. 507/6 a.C.), em que os atenienses, lutando em dois frontes, fo-

\footnotetext{
" Professor Doutor de Língua e Literatura Grega da Universidade Federal do Ceará.

"Artigo recebido em 26.jul.2014 e aceito para publicação em 30.set.2014.

1 "E os atenienses prosperaram. Fica assim evidente, não somente com relação a um aspecto, mas de um modo em geral, o quanto a igualdade de voz e voto (isēgoriâ) é algo excelente; pois se eles, porquanto tiranizados, em nada eram superiores a seus vizinhos na lide da guerra, uma vez libertados dos tiranos, tornaram-se, de longe, os primeiros. Tudo isso demonstra, sem sobre de dúvida, que, quando oprimidos, fingiam ser covardes, como se trabalhassem para um senhor, mas que, libertos, cada um deles zelava para atingir grandes feitos [em combate]."
} 
ram capazes de derrotar primeiramente os espartanos liderados por Cleomenes para, em seguida, enfrentar os beócios, ainda no continente e, no mesmo dia, cruzarem para a ilha da Eubeia e derrotarem os calcídios, dessa forma afastando de uma vez por todas o perigo de uma reinstaurarão da tirania na cidade de Atenas, como era a intenção da campanha espartana.

Esses epigramas são importantes por pelo menos três motivos. Em primeiro lugar, o III FGE é citado por Heródoto como uma forma de salientar o crescente protagonismo da cidade de Atenas em defesa da liberdade e, de certa forma, aparece no ponto de inflexão em sua narrativa, isto é, quando, libertada do jugo dos filhos de Pisístrato, o povo de Atenas engaja-se em uma série de campanhas militares que irão visar a preservação do recém-instaurado governo democrático tanto contra inimigos internos, como os espartanos, quanto externos, como os persas. O evento da Batalha Calcídia, portanto, serve de pano de fundo para os grandes feitos de coragem que serão narrados nos livros seguintes, como a Batalha de Maratona e as subsequentes campanhas contra os persas. Dessa forma, esse episódio da guerra contra espartanos, beócios e calcídios também serve para, etiologicamente, explicar os sucessos posteriores dos atenienses ao integrá-lo à narrativa como uma espécie de marco inaugural de uma série temporal em que o crescimento ${ }^{2}$ de Atenas, de mero poder regional a principal protagonista das Guerras Médicas e, posteriormente, à império marítimo, é enquadrado como o "destino manifesto" de um povo regido por um determinado sistema político aparentemente favorecido pela própria narrativa do historiador. ${ }^{3}$

Em segundo lugar, os dois epigramas revelam uma linguagem claramente influenciada por uma ideologia que já valorizava o coletivo em detrimento do individual, numa importante mudança de paradigma no que diz respeito aos valores aristocráticos presentes em inscrições do período arcaico. Nos dois epigramas sob análise, ao invés de termos a fórmula "fulano, filho de $x$, da cidade $y$ fez $z^{\prime \prime}$ temos a expressão de uma coletividade manifestada, na primeira inscrição, por meio de dêicticos ${ }^{4}$ que reforçam a ideia de um esforço de guerra pelo bem comum do $\delta \tilde{\eta} \mu o \varsigma$, que, em troca, se

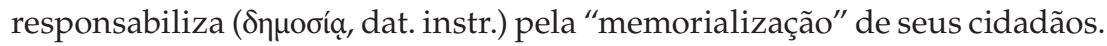
Na segunda inscrição, por outro lado, salta aos olhos a expressão "filhos de Atenas", que não deixa espaço para a glorificação de generais ou de guerreiros que possam ter se sobressaído no campo de batalha. Ainda mais, notase aí uma clara mudança de perspectiva no que tange à responsabilidade

\footnotetext{
2 Aǚnøıc, uma palavra chave para o Livro 5, cf. a epígrafe, por exemplo.

${ }^{3}$ Cf. os discursos de Otanes, Megabizo e Dario no Livro 3.80 et seq.

${ }^{4}$ Pronomes e desinências número-pessoais apenas: $\eta \tilde{\mu} \tilde{v},-\mu \varepsilon v$, -ot.
} 
pela vitória na guerra e pela punição da soberba (üßpı)) dos homens: muito embora a oferenda deixe claro a gratidão dos combatentes à deusa tutelar da cidade, são eles próprios, e não os deuses, ou a deusa, os responsáveis por "extinguir" a soberba dos inimigos e, consequentemente, a sua própria exaltação ocupa a maior parte da inscrição, ao passo que a menção à deusa resume-se à uma única palavra, Пá $\lambda \lambda \alpha \delta \mathrm{t}$, "para Palas".

Uma outra razão para tratar desses dois epigramas em conjunto é que, se assumirmos que eles se referem a um mesmo evento (com o que a maior parte da crítica parece concordar), mas, sobretudo, que a voz que fala por meio de ambos é a dos atenienses - i.e., a dos mortos em combate, no primeiro epigrama, e a dos sobreviventes, no segundo -, como pretendo argumentar, então temos aí um raro exemplo de duas inscrições com propósitos bastante distintos para uma mesma ocasião, ${ }^{5}$ mas que, apesar disso, aparentam preservar uma surpreendente coerência temática em termos de estilo e dicção, o que apontaria para um mesmo autor. Infelizmente, como veremos, o primeiro epigrama nos foi transmitido apenas pela via literária, mas há razões para se crer que ele possa ter sido de fato uma inscrição real, provavelmente gravada em algum tipo de monumento erigido no próprio local da batalha, onde os guerreiros teriam tombado, ou então, como acredito ser mais plausível, na cidade de Atenas, acompanhado por uma lista contendo o nome dos mortos.

\section{TEXTO $^{6}$}

FGE II

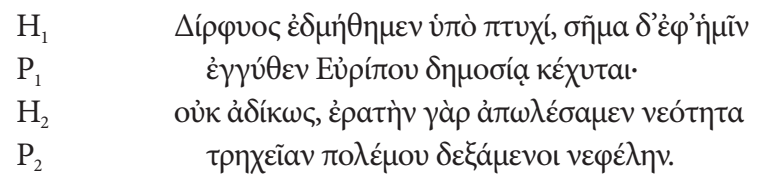

Domados sob um vale de Dirfi, um sinal sobre nós, perto do Euripo, pelo povo foi deitado:

Não injustamente, pois a amável mocidade arruinamos, ao enfrentar do combate a áspera nuvem.

\footnotetext{
${ }^{5}$ Quais sejam esses propósitos irei discutir na próxima seção.

${ }^{6}$ II e III FGE: Page 1975, respectivamente, acrescidos de sinais editoriais.
} 
FGE III

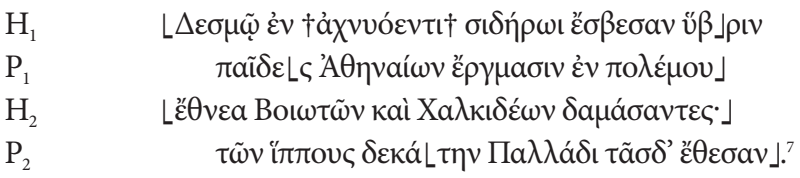

Num dolente grilhão de ferro, extinguiram a soberba os filhos de Atenas, nos trabalhos de guerra, hordas de beócios e de calcídios após terem dominado: desses cóo dízimo estas éguas ${ }^{8}$ à Palas dedicaram.

\section{EDIÇÃO E FORTUNA CRÍTICA9}

O epigrama Sim. II FGE é fruto da transmissão literária apenas, aparecendo unicamente no apêndice à Antologia de Planudes (APl), sob o cabeçalho " $\Sigma \mu \omega v i ́ \delta o v ",{ }^{10}$ ou seja, [da obra/epigramas?] de Simônides, o que indica que ou já deveria estar disponível no assim chamado "Sylloge Simonidea" (c. 100 a.C. $)^{11}$ ou que poderia ter sido transmitido via uma tradição mais antiga, já que os todos os epigramas desta seção da APl, que são oriundos de inscrições que acompanhavam obras de arte, não se encontram na Antologia

${ }^{7}$ Os sinais L e ل Iindicam o texto recuperado dos remanescentes arqueológicos.

${ }^{8}$ Isto é, as estátuas das éguas a puxar uma quadriga, cf. Heródoto 5.77 e mais abaixo. A menos que indicado em contrário, todas as traduções são minhas. Cf. também Brose 2008, Brose 2011.

${ }_{9}^{9}$ A menos que seja indicado em contrário, todos os autores antigos foram consultados usando-se a base de dados do TLG-E (Thesaurus Linguae Graecae, [Calif.]: University of California, Irvine, 2000) e PHI (Latin Library, Packard Humanities Institute, PHI v. 5.3 CD-ROM, 1991) por meio do programa Diógenes v. 3.1 (Disponível em <http://www.dur.ac.uk/p.j.heslin/Software/Diogenes/ index.php $>$, acesso em junho de 2014) e, portanto, a numeração de referência apresentada nas citações segue o padrão adotado nas edições daquelas coleções.

${ }^{10}$ Paton 1979, 5.16 .26 (também Simônides 89; Bergk 87 D). Sobre a pertinência dessa indicação de autoria a Simônides, ver mais abaixo a discussão sobre o P. Oxy. 2535 e a n. 23.

${ }^{11}$ A Sylloge Simonidea é um arquétipo teórico donde teriam sido extraídos os epigramas que lhe são atribuídos em muitas outras $\sigma 0 \lambda \lambda$ oүaí. As primeiras coleções desse tipo de que temos notícias são as assim chamadas "Coroas": a de Meleagro" (c. séc. I a.C.), a de Filipe (do período Augustano) e o "Ciclo de Agatias", do período Justiniano, reunidas por Constantino Cefalas na Antologia Palatina (AP, c. séc. x d.C.), cujo único manuscrito encontra-se Biblioteca Palatina, em Heidelberg. Outras prováveis fontes utilizadas por Cefalas foram epigramas retirados de escritores bem conhecidos em sua época: da Musa Puerilis, de Estratão (Livro XII), uma coleção de poesia amorosa de Rufino e epigramas de Paladas (séc. v d.C.), cf. Paton 1979, v et seq.. No séc. XII ou XIII d.C. o erudito Máximo Planudes reeditou o trabalho de Cefalas, dando origem ao que hoje conhecemos como a Antologia de Planudes. Sobre a possibilidade de que os epigramas de Simônides possam ter sido coletados ainda durante a vida do poeta, cf. Sider 2007. 
Palatina (AP).$^{12}$ De acordo com Page, ${ }^{13}$ o estilo, o tema e o tom do epitáfio estão de acordo com a temática daquela coleção. Ao contrário do III FGE, esse epigrama nunca recebeu muita atenção da crítica especializada.

A história da transmissão e estabelecimento do texto do Sim. III FGE, por outro lado, é bastante mais variada e produziu uma bibliografia considerável a partir do séc. XIX. ${ }^{14}$ Mesmo sua autoria é disputada pela maior parte dos especialistas, já que as quatro fontes antigas ${ }^{15}$ que o citam são vagas a esse respeito. A ideia de inseri-lo numa coletânea de epigramas de Simônides veio, na verdade, de seu primeiro editor moderno, Schneidewin, ${ }^{16}$ em 1835, seguido por Bergk, ${ }^{17}$ em 1882. Ambos citam as vinte linhas do Пepì

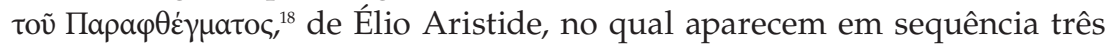
epigramas atribuídos a Simônides (21, 38, e 45) finalizados por um excerto do III FGE. ${ }^{19}$ Page,${ }^{20}$ no entanto, herdeiro da cautela de Kaibel, ${ }^{21}$ e retomando o argumento de Boas, ${ }^{22}$ defende que apenas a proximidade do nome não seria suficiente para que a autoria de qualquer um dos epigramas seja atribuída a Simônides, não obstante o fato de que ele é mencionado, juntamente com Píndaro, antes e depois dos exemplos supracitados.

Em 1995, contudo, E. G. Turner ${ }^{23}$ publicou um papiro, oriundo da antiga cidade egípcia de Oxirrinco (moderna el-Bahnasa) e datado do final do século i d.C., em que é possível se reconstruir o nome $\Sigma \mu \omega v$ เ $\delta$ - a partir das letras ] $\mu \omega v$ เ $[$ que aparecem logo acima de uma parte identificável do

${ }^{12}$ Paton $(1979$, v) supõe que os epigramas do apêndice da APl tenham pertencido a um livro perdido da coleção de Cefalas.

${ }^{13}$ Page 1981, 189.

${ }^{14}$ Cf. Page (1981, 189 n.13, passim) e Petrovic (2007, 209) para uma lista de comentadores modernos.

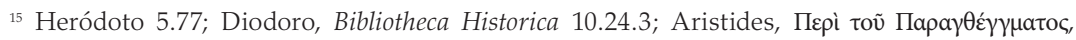
380.20 e a Anthologia Planudeae 6.343. O copista A da Antologia Palatina é bem explícito nesse sentido, ao acrescentar, ao fim do epigrama, "a̋ $\delta \eta \lambda o v^{\text {"; } ; ~ o ~ c o p i s t a ~ d e ~} \mathrm{C}$, aparentemente referindo-se

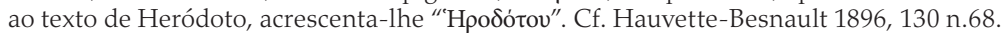

${ }^{16}$ Schneidewin 1835, 176: "Ceo poetae vindicamos auctoritate Aristidis $\pi \varepsilon \rho \iota \pi \alpha \rho a \varphi \theta \varepsilon \dot{\gamma \mu} \mu$ III, p. 647. Canter."

${ }^{17}$ Bergk 1878-1882, 784.

${ }^{18}$ Aristid. 380.2-22.

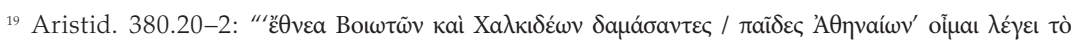

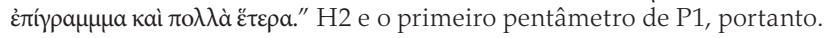

${ }^{20}$ Page 1981, 189.

${ }^{21}$ Kaibel 1878, 304 (ep. 748): "Simonidem epigramma non fecisse vel inde adparet quod cum litterae tituli ol. 82 antiquiores non essent verissime conlegit Kirchoff tempore posteriore arce a Pericle magnifice redintegrata epigramma incisum esse."

${ }^{22}$ Boas 1905, 92-6.

${ }^{23}$ P. Oxy. n. 2535, in P. Oxy. vol.31, edited by E. G. Turner (1996). Uma foto do papiro pode ser acessada no site Oxyrrhynchus Online, mantido pela Universidade de Oxford (http://www. papyrology.ox.ac.uk/POxy/ees/ees.html, acessado em julho de 2014). Uma primeira análise do papiro foi feita por Turner 1962 e, posteriormente, por Sider 1976. 
III FGE, ${ }^{24}$ sendo que um genitivo, i.e., $\Sigma \mu \omega v i ́ \delta o v$, parece ser uma opção bastante plausível, se não a única que faça algum sentido. Ainda que essa não seja uma prova inatacável de autoria, ela é uma forte evidência de que, no mínimo, existia na Antiguidade uma tradição de atribuir essa inscrição a Simônides, algo que, devido ao impasse atual da pesquisa, já é uma importante descoberta.

Uma das poucas coisas de que se tem certeza, aliás, é de que o epigrama foi, de fato, uma inscrição real, uma vez que os remanescentes arqueológicos de duas bases de pedra foram encontrados, durante escavações realizadas entre 1869 e 1887 , nas quais se pode identificar o texto dos epigramas. ${ }^{25}$ São dois grupos de fragmentos de épocas distintas, identificados a partir daqui como (a) e (b). ${ }^{26}$

$\mathrm{O}$ pedaço da base mais antiga (a), com dimensões de cerca de 30 $\times 51 \times 37 \mathrm{~cm}$, foi cortada em granito eleusino azulado e deveria ter originalmente por volta de $2,85 \mathrm{~m}$ de largura. Suas letras, gravadas no alfabeto ático, medem aproximadamente $3 \mathrm{~cm}$ de altura e foram cuidadosamente encaixadas na grade desenhada pelo artesão, embora a inscrição não tenha resultado numa disposição estíquica, ${ }^{27}$ ainda que disposta em dois dísticos compostos, cada um, de um hexâmetro seguido de um pentâmetro separados pelo sinal [ $\vdots$ ], algo usual a partir do vi século a.C. Esta base, junto com o monumento que lhe acompanhava, foi destruído pelos persas na invasão de 480 a.C., como veremos mais abaixo.

A base (b), mais recente, é, na verdade, um conjunto de quatro fragmentos de mármore pentélico, dos quais três são oriundos do lado direito da pedra e apresentam dimensões aproximadas de $17,5 \times 61 \times 41 \mathrm{~cm}$, enquanto o quarto, oriundo do lado esquerdo, mede cerca de $12 \times 12 \times 15 \mathrm{~cm}$. O tamanho original deve ter sido semelhante ao de (a). As letras de (b), gravadas no alfabeto ático e dispostas sobre uma superfície que foi, posteriormente, polida, medem cerca de 2,5 cm de altura e, ao contrário de (a) resultaram num arranjo estíquico. As evidências paleográficas permitem datá-la do início de séc. v a.C.

\footnotetext{
${ }^{24} \mathrm{H}_{2}$ seguido de $\mathrm{P}_{1}$, i.e., na ordem em que aparecem em Heródoto, veja mais abaixo.

${ }_{25}$ Para a descrição original, cf. Kirchhoff 1887, Sitzungsberichte der Akademie zu Berlin (p. 112), não consultado por mim. De acordo com Hicks (1901, 13 n.12): (a) "[was] found in the ruins of a large building NE. of the Propylaia" e (b) "[was] discovered on the Acropolis". Petrovic (2007, 211) alega que o local onde os fragmentos de (b) foram descobertos é desconhecido e que apenas a data (1869) inscrita no fragmento oriundo lado direito pode ser determinada com precisão.

${ }^{26}$ Respectivamente, IG I 394 (c. 507) e IG I 334 (a) e 373 (c. 457-446).

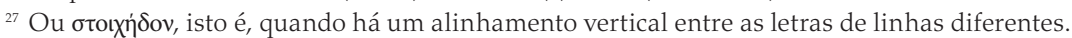
Os gravadores costumavam desenhar uma grade a carvão, em cujos quadrados eram, então, inscritas as letras.
} 
A identificação das inscrições com os epigramas transmitidos pela via literária está assegurada pela superposição da menção ao dízimo e às

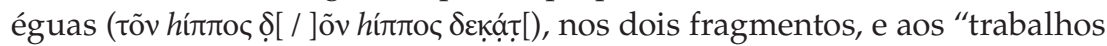

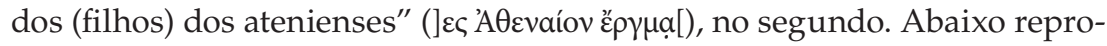
duzimos a transcrição epigráfica das duas bases, colocando em negrito o texto da pedra, para distingui-los dos suplementos editoriais ${ }^{28}$ :

(a)

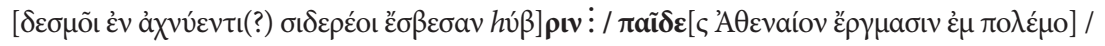

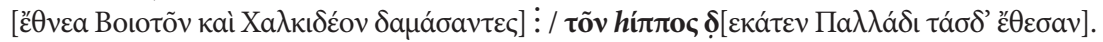

(b)

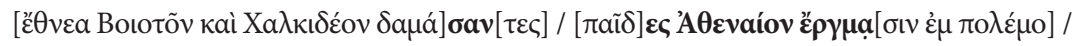

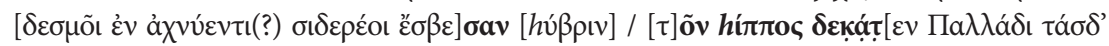
है $\theta \varepsilon \sigma \alpha v]$.

Um fato que imediatamente chama a atenção é que o fragmento (b), mais recente, tinha os hexâmetros na mesma ordem das quatro fontes literárias que o citam, ${ }^{29}$ i.e., o primeiro dístico começando $\varepsilon^{\prime} \theta v \varepsilon \alpha \kappa \tau \lambda$. e o segundo, $\delta \varepsilon \sigma \mu \tilde{\omega} \iota \kappa \tau \lambda$. O fragmento (a), contudo, apresentava uma ordem inversa, o que nos permite concluir que os autores responsáveis pela transmissão do texto só tiveram acesso a (b). É muito provável, portanto, que (a) tenha sido destruído (junto com o monumento que portava) durante a invasão persa de $480 / 79$ e que, mais tarde, ${ }^{30}$ uma reconstrução tenha sido levada a cabo, ocasionando, por razões não de todo claras, a inversão dos dísticos quando da gravação da nova base (b), certamente uma cópia da base do monumento original. ${ }^{31}$

Heródoto, ${ }^{32}$ nossa fonte mais antiga, faz referência à destruição promovida pelos persas enquanto menciona a inscrição que, segundo ele, podia ser vista na base de uma quadriga de bronze construída com um décimo do resgate dos cativos beócios, precisamente como mencionado no epigrama, à esquerda de quem entrava no Propileu em direção à Acrópole:

${ }^{28} \mathrm{IG} \mathrm{I}^{3}, 501$ (IG I².394,II/I; DAA 168, 173), in Searchable Greek Inscriptions: A Scholarly Tool in Progress. The Packard Humanities Institute, 2012 (disponível em http://epigraphy.packhum.org/ inscriptions/main, acessado em julho de 2014).

${ }^{29}$ Page 1981, 192. Vide nota 15, acima.

${ }^{30}$ Talvez para celebrar a vitória dos atenienses em Oinófita (c. 457), assim West (1985, 283), Hauvette (1896) e outros. Cf. Petrovic 2007, 211. Sobre a Batalha de Oinófita, vide Tucídides 1.108.

${ }^{31}$ Do qual (a) deve ser um dos fragmentos.

325.77 et seq. 
haveria diferença entre os cativos e o dinheiro que poderia ser pago por eles: como propriedade dos vencedores seu valor de troca estava assegurado e, assim, referir-se aos mesmos através do relativo genitivo plural $\tilde{\omega} v$ seria de uma sutileza e humanismo estranho aos vencedores.

Da mesma forma é digno de nota que a ordem original, revelada pelas pedras, põe em relevo os grilhões com os quais os atenienses teriam extinguido a soberba dos inimigos, ao anunciá-los desde o primeiro verso. Grilhões estes que, ostensivamente pendurados no muro, deveriam, integrar, de certa forma, toda a "instalação" (como modernamente caracterizaríamos esse conjunto de $\mu v \eta \dot{\mu a \tau} \alpha$ ) da oferenda, destinada a propalar a superioridade militar da cidade e o valor que a liberdade democrática conferia aos seus cidadãos. ${ }^{39}$

Um último e espinhoso problema no estabelecimento do texto final, e que tem desafiado gerações de estudiosos diz respeito à discrepância de

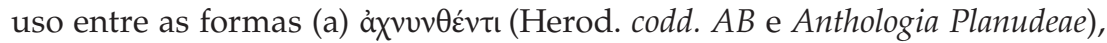

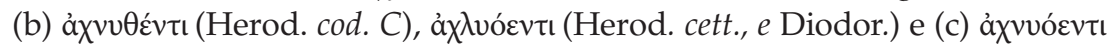
(Hecker).

Começando pela evidência da pedra, podemos perceber que a parte onde o adjetivo apareceria se perdeu. Reorganizando os dísticos de acordo com a reconstrução paleográfica (bastante precisa numa disposição estíquica ${ }^{40}$ ), percebemos que sobram apenas oito espaços onde encaixar uma das possíveis variantes, o que, prima facie, excluiria definitivamente

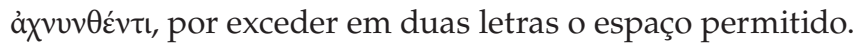

Seja como for, nem ả $\chi v v v \theta \varepsilon ́ v \tau ı$ nem mesmo ả $\chi v v \theta \varepsilon ́ v \tau ı$ (essa última, com nove letras) são possíveis aqui e por diversas razões, além da falta de

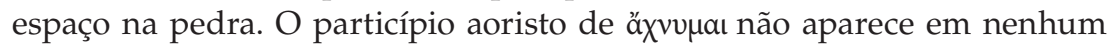
texto $^{41}$ transmitido e, embora a possibilidade de um hapax não possa ser

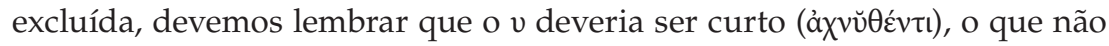
é permitido pela escansão do hexâmetro, já que implicaria no monstrum

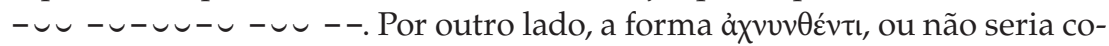
mum nesse período, segundo Page, ou impossível, segundo West. ${ }^{42}$

${ }^{39}$ Cf. Heródoto 5.78.

${ }^{40} \mathrm{Cf}$. nota 27.

${ }^{41}$ De acordo com Page $(1981,193)$ não faz o mínimo sentido o argumento de Friedländer (1948)

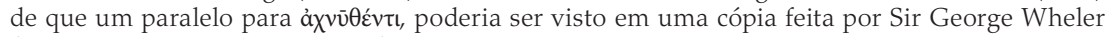
(Brit. Museum Add. MS 35,334) feita em 1676 durante sua visita a Atenas e posteriormente

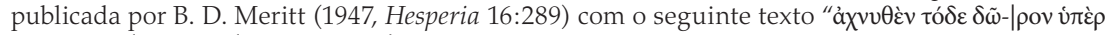

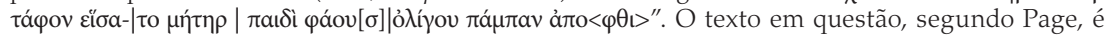
muito mais tardio, talvez mais de seis séculos, e Peek (GVI, n. 238, 62) está provavelmente correto

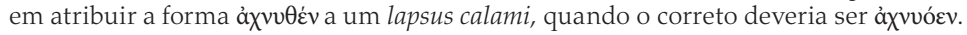

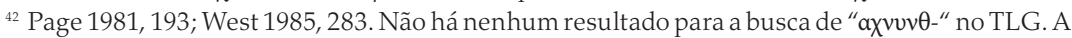
despeito disso, a alegação de Page, ecoada porWest, de que o significado "painful, grievousisincred- 


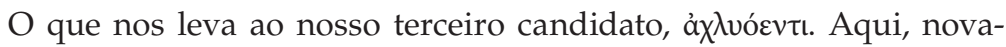
mente, temos uma letra a mais do que deveríamos, mas, de resto, o sentido parece ser adequado se levarmos em conta os paralelos encontrados em ou-

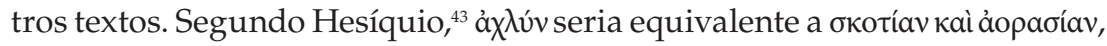

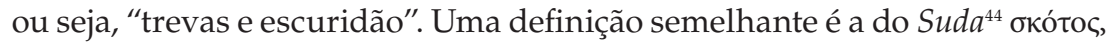

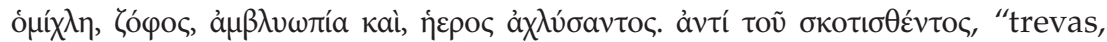
fumo, escuridão (como a do Érebo), visão embaçada, também [quando o] céu está escurecido. O mesmo que enegrecido". A partir dessas definições poderíamos estender o conceito aos grilhões com que os beócios e calcídios foram subjugados, uma vez que o ferro, ainda que brilhante quando novo, ou polido, enegrece facilmente em contato com o ar, devido ao processo de oxidação de sua camada exterior, formando Óxido de Ferro $\left(\mathrm{Fe}_{3} \mathrm{O}_{4}\right){ }^{45}$ num primeiro estágio que, em seguida, pode prosseguir ou não, dependendo das condições atmosféricas e de umidade, para a ferrugem (Hidróxido de Ferro, $\mathrm{Fe}_{2} \mathrm{O}_{3}+3 \mathrm{H}_{2} \mathrm{O}$ ) propriamente dita. ${ }^{46}$

Ainda com essa acepção, o adjetivo poderia se referir ao sangue ou aos líquidos purulentos que certamente escorreriam dos tornozelos infeccionados dos prisioneiros amarrados daquela forma, cobrindo a superfície já enferrujada do metal e dando-lhe a uma aparência enegrecida. ${ }^{47}$ Dentro desse campo metafórico em que escuridão e dor se combinam, encontra-

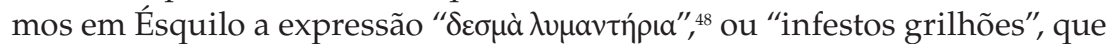
se refere às calcetas de Prometeu. "Infestos" porque corrompem não só sua carne, mas também sua honra, ao rebaixarem-no a uma condição de cativo. A corrupção do ferro, através da ferrugem, é assim equacionada por Ésquilo à corrupção do corpo de Prometeu e com ela anda pari passu. ${ }^{49}$

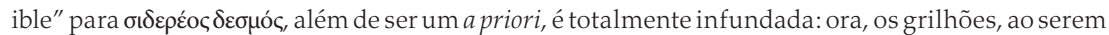
friccionados contra os tornozelos, durante a viagem até a cidade do inimigo, poderiam ser capazes de causar terríveis lacerações e, portanto, não poderiam ter uma denominação mais apropriada.

${ }^{43}$ Lexicon, alpha, 8851.

${ }^{44}$ Alpha, 4704.

${ }^{45}$ Esse óxido ferroso pode ser criado propositadamente através de técnicas de aquecimento do ferro, servindo como uma camada protetora contra a ferrugem propriamente dita.

${ }^{46}$ Uma hipótese já aventada (ainda que por razões diferentes) por Friedländer (1948, 136):

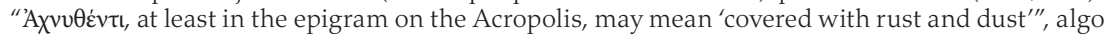
que Page (1981, 193 n.1) descarta: "It could not possibly mean 'covered with rust, as Friedländer

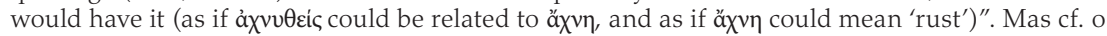

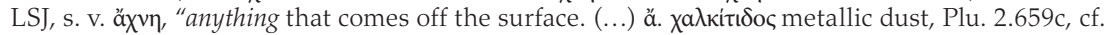
Orph. L. 455" [grifo nosso] e a passagem de Políbio citada na nota 49, abaixo.

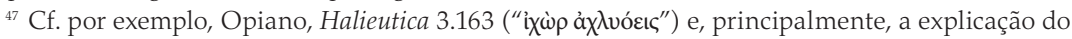

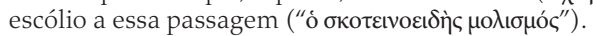

${ }^{48}$ Ésquilo, Prometeu Acorrentado 991.

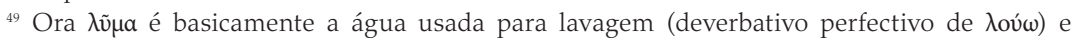
descartada por ser suja; é também a água estagnada dos pântanos e, por extensão de sentido, todo

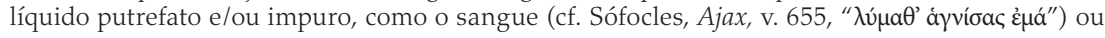


Mesmo sendo tida como espúria por alguns comentadores, como Page e West - pelas razões erradas, a nosso ver ${ }^{50}$ - o efeito causado pelo

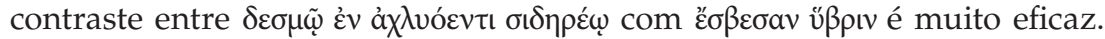
O verbo $\sigma \beta \varepsilon ́ v v v \mu$ tem o sentido prototípico de "apagar, extinguir, remover da vista, fazer desaparecer" ${ }^{51}$ Consequentemente, talvez a ideia pretendida fosse que a üßpı dos invasores, vista como uma espécie de fogo ou chama, seria "apagada" ou "obscurecida, obnubilada" pelas trevas da escravidão, cujo instrumento aparente seria os grilhões de ferro. Não é demais notar que na Teogonia, Zeus pune a üßpı de Menécio ${ }^{52}$ lançando-o ao Êrebo, aí

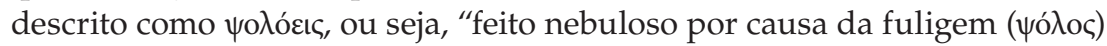
no ar", para onde, pelo mesmo motivo, também são enviados os Titãs e os deuses prístinos.

Se a soberba pode sempre ser rebaixada e "apagada", o contrário

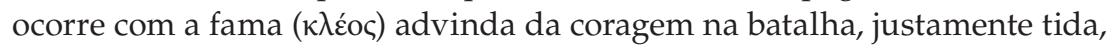

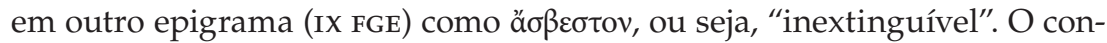
traste entre a luz ou fogo, sugerido pela junção entre $\sigma \beta \varepsilon ́ v v v \mu$ e $u ß \beta \iota v$, de

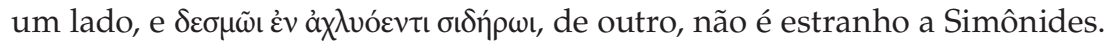
Nunca se poderá descartar uma atribuição de autoria por parte dos antigos baseando-se simplesmente no estilo ou no que acreditamos ser ou não uma dicção poética adequada. Nesse caso, essa ressalva é ainda mais importante, já que Simônides sempre foi famoso por sua peculiaridade no uso expressivo da língua e pela tendência em criar novos vocábulos a partir da sinestesia, ${ }^{53}$ dos quais os mais interessantes têm justamente a ver com o jogo

o prurido das feridas. $\Lambda u ́ \mu \eta$, a forma ática, ainda se relaciona com o sentido de "infenso, nocente, deletério, prejudicial" tanto física quanto moralmente. Surpreendentemente, é o adjetivo usado

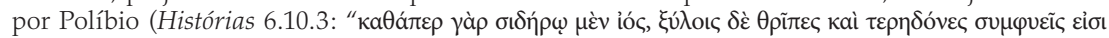
$\left.\lambda \tilde{u} \mu a^{\prime \prime}\right)$, para caracterizar a decadência do ferro através da ferrugem.

${ }^{50}$ Page 1981, 193, 1 [692]: "ảx $\lambda$ úç is mist; its adjective is unsuitable to such a noun as fetters,

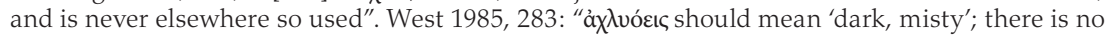
parallel for the figurative sense 'gloomy, dismal' offered in the LSJ". As evidências não descartam completamente um uso metafórico de ảx $\lambda$ úc como escuridão ou mesmo tristeza, como é o caso

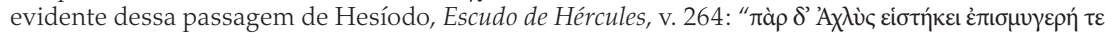

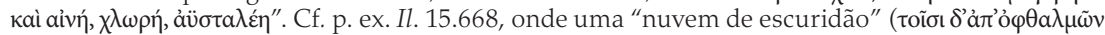

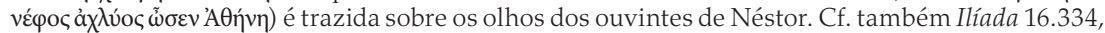
20.321,20.341, 20.421 e, em um sentido mais metafórico Od. 7.41, 20.357 (escuridão trazida pelo pôr do sol) e 22.88. Beekes (2009, 184, s.v., ảx入úc) nota que Arm. ałj̆-a-m-ułǰ-k’ (pl.), derivado do mesmo radical, significa "escuridão".

${ }^{51}$ Mallory e Adams 2006, 214: "Finally, there is wide agreement in meaning, if not in phonetics, for a verb * $g^{w}$ es- 'extinguish' seen in Baltic (eg. Lith gèsti), Slavic (OCS ugasiti), Grk sbénnūmi, Anatolian (Hit kist-), Skt jásate, and Tocharian (Toch B kes-), which all indicate 'go out, extinguish'." Cf. também Pokorny, IEW, s.v. g ${\text { ges-, } z g^{\prime \prime} e s-.}^{-}$

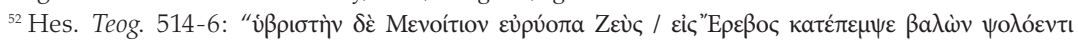

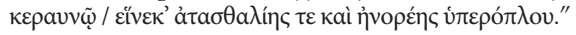

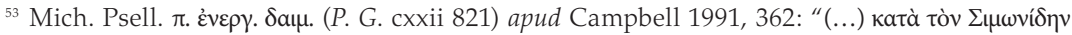

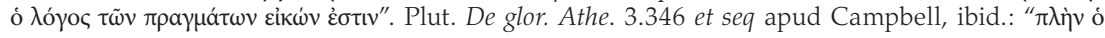




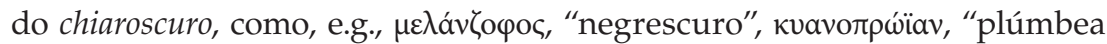

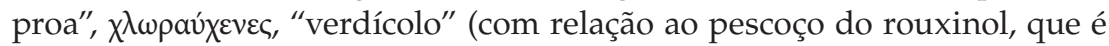

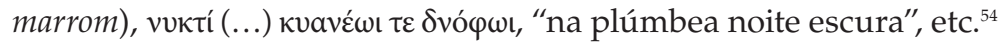

Resta-nos então analisar a sugestão de Hecker, ${ }^{55}$ ảxvvóevtı, que, de fato poderia ter dado origem à ả $\chi v v \theta \varepsilon ́ v \tau \iota$ e, daí, à ả $\chi v v v \theta \varepsilon ́ v \tau \iota$, uma vez que o ômicron epigráfico (principalmente no início do $\mathrm{v}$ século) distingue-se do theta apenas por um ponto colocado dentro do círculo, o que poderia

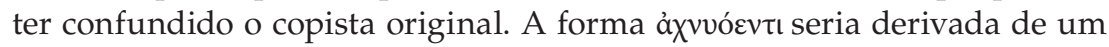
substantivo, ảxvúc, jamais atestado, a não ser por uma única entrada no Etymologicum Genuinum Magnum, onde aparece como glosa de "í $\lambda u ́ \pi \eta$ ”, o que combinaria com o sentido do epigrama. De qualquer maneira, ainda teríamos nove letras para um espaço onde caberiam apenas oito, o que nos leva a considerar a alternativa proposta pelos epigrafistas (atualmente in-

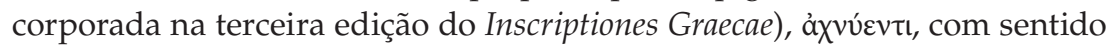
idêntico ao da forma com ômicron. O problema com essa variante é que ela é um construto hipotético, jamais tendo sido atestada (uox nihili, daí o uso das adagas no original) e, portanto, de forma nenhuma deveria ser incorporada no texto, mas relegada a um suplemento no rodapé.

Frente a essa situação desanimadora, só nos resta esperar para que um outro fragmento da pedra, contento o resto da inscrição, possa ser um dia desenterrado ou que um papiro surja que possa nos fornecer uma alternativa mais plausível, se não da própria inscrição, pelo menos de uma passagem que contenha vocabulário semelhante capaz de validar algum dos suplementos propostos ao longo dos anos para melhorar o texto. Finalmente, não é impossível, embora seja bastante improvável, que o original contivesse um adjetivo completamente diferente do que nos foi passado por Heródoto, Diodoro ou a Antologia, ou que a inscrição, que nos parece regularmente estíquica contivesse alguma espécie de rasura ou desigualdade no espaçamento das letras.

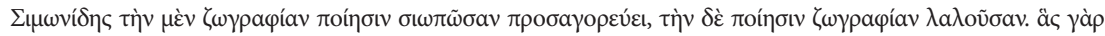

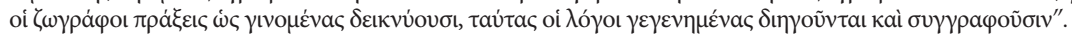

${ }^{54}$ Respectivamente Fr. 630 PMG; Fr. 625 PMG; Fr. 586 PMG; Fr. 543 PMG, 11-12.

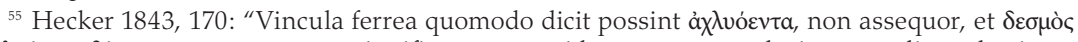

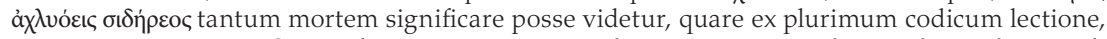

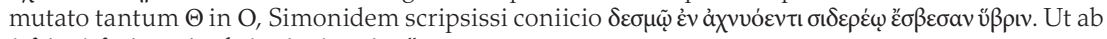

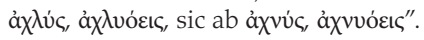




\section{TEMA, OCASIÃO E CLASSIFICAÇÃO}

Os dois epigramas dizem respeito ao conturbado período entre os anos 508-506, após a derrocada da tirania, a luta entre Clístenes e Iságoras pela liderança política e a expulsão definitiva do exército espartano, liderado por Cleomenes, da Ática. Esse último, aliás, ao saber que os atenienses haviam chamado de volta as inúmeras famílias exiladas durante o breve governo de Iságoras e, sobretudo, por sentir-se humilhado devido a sua fuga inglória da Acrópole sob o cerco do povo, decide mais uma vez, acompanhado de Demárato, tentar um último movimento para submeter os atenienses, como nos conta Heródoto (5.74):

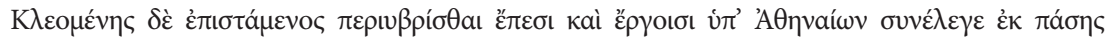

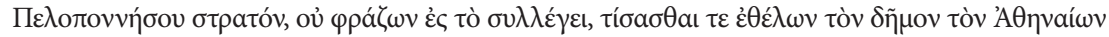

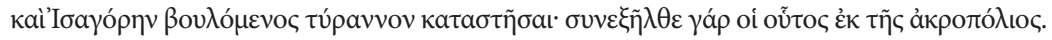

Mas Cleomenes, consciente de ter sido ofendido tanto em palavras quanto em atos pelos atenienses, selecionou um exército dentre todas [as cidades] do Peloponeso, sem dizer para que o fazia: desejando vingar-se do povo de Atenas e querendo impor Iságoras como tirano, esse mesmo que, junto com ele, havia fugido da Acrópole.

Ainda segundo aquele historiador, essa ofensiva de Cleomenes contra a Ática desenrolou-se em três frontes distintos, e deve ter sido planejada com antecedência com seus aliados ${ }^{56} \mathrm{O}$ plano seria o seguinte: os espartanos, com a ajuda dos coríntios, viriam do oeste, através do estreito de Corinto; os beócios, do nordeste, pelo vale do Monte Citáiro que margeia a foz do rio Asopo, perto do Euripo, ${ }^{57}$ enquanto os calcídios, atravessando esse mesmo estreito, pretendiam avançar sobre a costa leste da Ática vindo da Eubeia.

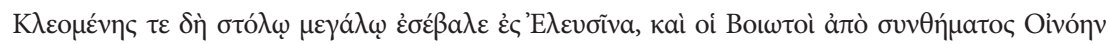

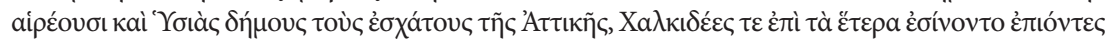

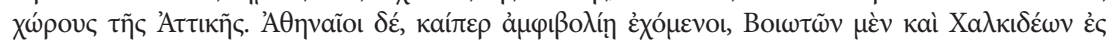

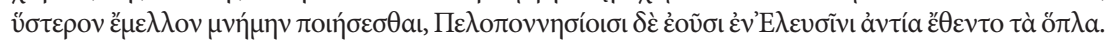

Cleomenes juntamente com um grande contingente já marchava sobre Elêusis, quando os Beócios, à partir de um sinal previamente acordado, tomaram os demos de Oinoé e Hísia, na fronteira com a Ática; os calcídios, invadindo, adentraram a outra parte do território ático. Os atenienses, assim atacados em dois frontes, decidiram lidar com

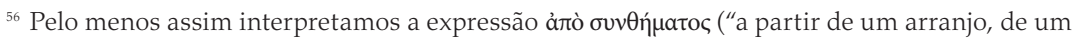
sinal prévio", cf. citação abaixo).

${ }^{57}$ O Euripo é o estreito que separa a Eubeia da Ática. A estela deveria localizar-se na cidade de Cálcis ou imediações; a batalha, no entanto, deve ter se realizado no vale da montanha de Dirfi (1745 m), a cerca de 10 km à nordeste de Cálcis.
} 
os Beócios e Calcídios por último - como veremos - e, consequentemente, contra os peloponésios, que estavam em Elêusis, ${ }^{58}$ viraram suas armas. ${ }^{59}$

Algo aconteceu, no entanto, que fez com que os coríntios resolvessem abandonar a ofensiva, seguidos de Demárato ${ }^{60}$ :

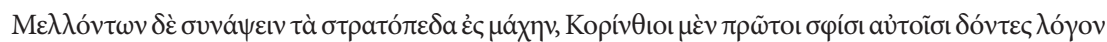

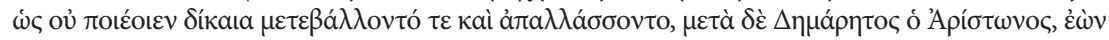

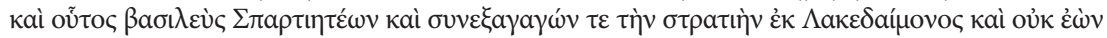

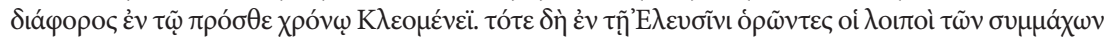

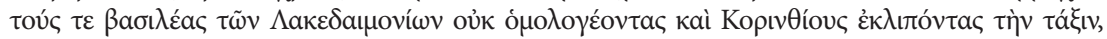

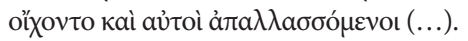

Quando as tropas já estavam a ponto de entrar em formação de batalha, os coríntios foram os primeiros a mudaram de ideia e abandonarem o combate, argumentando entre si que estariam cometendo uma injustiça. ${ }^{61}$ Em seguida, Demárato, filho de Arístão, sendo também rei entre os espartanos, e comandante-adjunto do exército lacedemônio, tomou a mesma atitude, embora ainda não tivesse, nessa época, qualquer diferença com Cleomenes. E foi então que o restante das tropas aliadas em Elêusis, vendo os reis dos lacedemônios discordantes e os coríntios já deixando a formação, partiram, sentindo-se igualmente desobrigados [de combater] (...). ${ }^{62}$

Inseridos no contexto dessa série de batalhas que garantiram a continuidade da democracia ateniense, os dois epigramas fazem parte, no entanto, de momentos distintos nessa guerra e foram comissionados, igualmente, em monumentos com funções distintas. ${ }^{63}$ Embora haja consenso, tanto entre as fontes como entre os comentadores, de que III FGE fizesse parte de uma oferenda comemorativa, i.e., um ává $\theta \eta \mu \alpha$, as coisas complicam-se um pouco quando consideramos seu par, II FGE.

Wilamowitz foi o primeiro a descartar a natureza funerária de II FGE por causa da referência ao campo de batalha, ${ }^{64}$ um fato que Page admite ser

${ }^{58}$ O escoliasta de Aristófanes (Scholia Veterea, Lys. 273.1-9), nos fornece maiores detalhes do

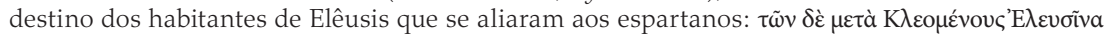

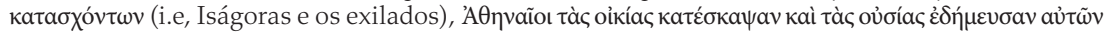

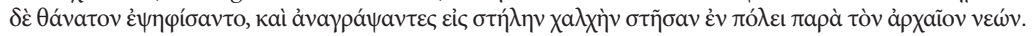

${ }^{59}$ Idem, n. 118, §75 et seq.

${ }^{60}$ Talvez a descoberta do verdadeiro propósito de Cleomenes (que era o de reinstaurar a tirania em Atenas) pois, como nos informa Heródoto, esse não o revelara ao reunir um exército (oủ

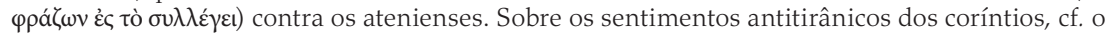
discurso de Sósicles, Heródoto 5.92 et seq.

${ }^{61}$ Contra os atenienses?

${ }^{62}$ Heródoto 5.75-6.

${ }^{63}$ Cf. Brose 2008, sobre a configuração dos monumentos públicos em Atenas entre os séculos VI-V a.C.

${ }_{64}$ "...wegen des angegebenen Kampfplatzes", apud Page 1981, 189. Outros que não reconheceram a inscrição como um epitáfio foram H. Von Gärtringen, Preger e Geffcken, citados apud Page, ibidem. 
incomum, embora não sem precedentes, já que, segundo ele, fosse essa regra seguida à risca, muitos epitáfios ${ }^{65}$ comprovadamente reconhecidos com base em evidências extraliterárias, deveriam ter sua classificação revista, o que não seria razoável. ${ }^{66}$ Não obstante sua certeza no que diz respeito ao caráter funerário da inscrição, Page nos surpreende ao aventar a hipótese de que seria a voz dos calcídios vencidos, e não a dos atenienses mortos em combate, ${ }^{67}$ aquela ouvida no epigrama. Assim, diz estranhar o fato de o texto mencionar o local de sepultamento, quando a estela onde ele estaria inscrito encontrava-se justamente dentro dos limites da cidade natal dos mortos, ou seja, Cálcis. No entanto, há pelo menos três problemas relacionados a essa sua interpretação.

O primeiro deles é que os combatentes teriam sido "vencidos ou do-

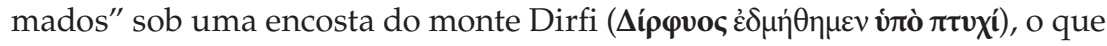
deslocaria o local da batalha em cerca de $16 \mathrm{~km}$ em direção ao interior da ilha $^{68}$ e tornaria possível, portanto, que os sobreviventes, seguindo o costume pan-helênico, tivessem decidido inumar os mortos imediatamente e

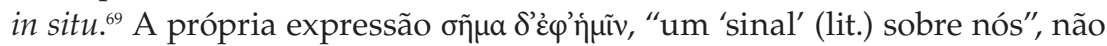
precisa exatamente o que estaria sobre os mortos; uma leitura que a traduza por "uma lápide sobre nós", por outro lado, acrescentaria ao verso mais informações do que disponíveis na inscrição, já que oñua pode indicar

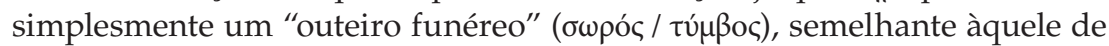
Maratona. Outrossim, o verbo $\chi \varepsilon u ́ w$, aqui na forma da $3^{a}$ p. do perf. sing. pass., tem, como se sabe, o sentido principal de "derramar, deixar escorrer", donde se desenvolve a noção de "amontoar" quando o objeto, expresso ou subentendido, é de natureza sólida, caso da terra depositada sobre os cor-

${ }^{65}$ Epitáfios que não mencionam nem a pátria nem o campo de batalha: Peek 8, 17, 26, 28, 29. Epitáfios que mencionam tanto a pátria como o campo de batalha: Peek 7, 9, 20. Epitáfios que nomeiam a pátria, mas não o campo de batalha: Peek 14. Epitáfios que nomeiam o campo de batalha, mas não a pátria: Peek 23.

${ }^{66}$ Page 1981, 189: "This objection [viz. Wilamowitz's], if true, would have a bearing on other epitaphs in the present collection (...)". Jacoby $(1945,160)$ descarta completamente o julgamento de Wilamowitz: "The objection of Wilamowitz (...) is shaky: the Corinthian epitaph from Salamis furnishes a sufficient parallel, and the Peisistratus epigram IG I2, 761 an even better one, not to mention later cases as, e.g., the second epigram for Chaeronea (Hiller 74)".

${ }^{67}$ Page 1975, 9: "hoc epigr. potius in victos quam victores compositum esse crederes". Assim também Friedländer (1948, 5 n.6), que exclui o II FGE de sua coleção por crê-lo literário: "we have not accepted Anth. Plan. $26=$ Simonides $89 \mathrm{BE}=87 \mathrm{Di}=116 \mathrm{Ed}$. In spite of A. Wilhelm's and F. Jacoby's positiveness (...), we feel quite uncertain whether the second distich is really

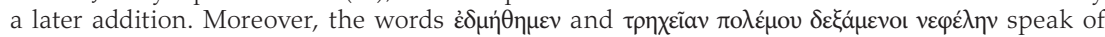
the vanquished rather than of the conquerors. Consequently the attribution to the victorious Athenians in 506 B.C. seems to us more than doubtful."

${ }^{68}$ Uma hipótese do próprio Page (1981, 191, 688-9).

${ }^{69}$ Para uma descrição mais detalhada do costume arcaico de enterrar os mortos diretamente no campo de batalha, cf. a análise do. XX FGE (IG 503 e 504) em Brose 2008. 
pos. Há inúmeras instâncias em que o verbo, aparecendo junto com $\sigma \tilde{\eta} \mu \alpha$,

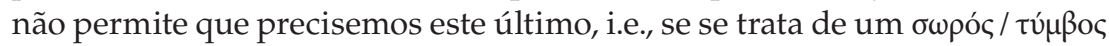
ou de uma estela inscrita, o que nos leva a admitir, portanto, que há pelo menos a possibilidade de que o epigrama possa ter sido colocado alhures, separado do outeiro funéreo a que faria referência.

O outro problema à "hipótese calcídia" de Page diz respeito à lógica textual do mesmo: foram os atenienses que saíram vitoriosos do combate contra os calcídios, não o contrário. ${ }^{70}$ Nessas condições e, do ponto de vista da ideologia da "bela morte", admitir a derrota em seu epitáfio não traria vergonha alguma para os que tombaram, simplesmente "porque é belo e justo morrer atacando na linha de frente, / para homem excelente lutando por sua pátria". ${ }^{71}$ Por outro lado, por que aqueles que, em troca de sua derrota (e tendo deixado livre o caminho para a queima das searas de sua cidade, da morte de seus filhos e da escravidão de suas mulheres) deveriam receber a "honra" de uma inscrição na pedra? Não seria isso algo para esquecer, mais do que para lembrar ou, pior ainda, celebrar? A honesta declaração de derrota, vista por Page com desconfiança por sua humildade excessiva, ${ }^{72}$ pode, em realidade, esconder uma manifestação do orgulho ateniense, ao declarar que esses, ferozes na batalha, só puderam ser "domados" por um povo exímio nesta arte e, mesmo assim, apenas alguns poucos, justamente por sua juventude (e consequente inexperiência), ressaltada de modo conspícuo na linguagem do epigrama. Se, ainda, estivermos corretos e os dois epigramas estiverem, de alguma forma, relacionados, o paralelismo temático entre ambos pode indicar que, talvez, também o II FGE pudesse fazer parte algum monumento ${ }^{73}$ contendo a lista dos nomes dos guerreiros mortos na guerra e estivesse localizado não na Eubeia, mas em Atenas, possivelmente em algum lugar da ágora. A ideia de que os calcídios possam ter comissionado o epigrama parece-nos um exercício de reductio ad absurdum que apenas reforçaria uma identificação com os mortos, porém vitoriosos, atenienses.

\footnotetext{
${ }^{70}$ Assim Molyneux 1992, 86.

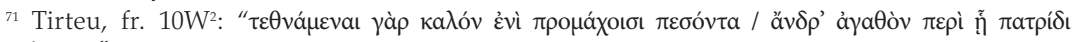

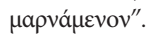

${ }_{72}$ Page 1981, 190: "The most unusual feature of II is the apparent admission of defeat. There

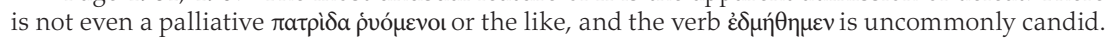
No other public epitaph for men fallen in battle states that they were 'overpowered', or even that they were defeated. (...) Plainly, if this epitaph refers to the events of 507/6 B.C., the men commemorated will be the defeated Euboeans, not (as is commonly supposed) the victorious Athenians."

${ }^{73}$ Aqui seria oportuno lembrar o que ressaltamos no início deste artigo: todos os epigramas do apêndice da APl parecem ter sido recolhidos de obras de arte ou monumentos. Ver nota 12.
} 
Uma última porém importante consideração deve ser feita, que, de certa forma, ajudaria a pesar o argumento a favor de uma autoria ateniense. O termo $\delta$ noớá, "às expensas do povo" (oposto à ióía, "às expensas próprias"), inusitado e, ademais, nunca atestado em nenhuma inscrição para a Eubeia no período considerado, é conspicuamente associado à democracia ateniense. Os decretos em que o povo ( $\delta \tilde{\eta} \mu \circ \varsigma)$ decidia os rumos da cidade e legislava sobre as mais variadas matérias, inclusive sobre as honras aplicáveis aos mortos de guerra ou a indivíduos particulares, invariavelmente

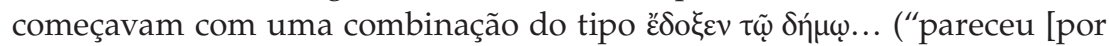

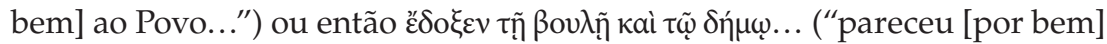

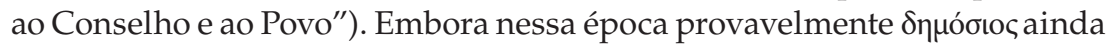
não tivesse a conotação que desenvolveria mais tarde (no contexto da instituição do patrios nomos, por exemplo). A própria menção a uma palavra tão técnica do vocabulário jurídico ateniense, sobretudo num período imediatamente posterior às reformas de Clístenes, deveria, na falta de evidências em contrário, ser suficiente para atribuir a autoria da inscrição ao povo de Atenas, identificando-se nela a voz dos soldados que sacrificaram suas vidas numa batalha não só crucial, mas decisiva para o fortalecimento da democracia, já que uma derrota nessa empreitada poderia ter levado a stasis e a tirania outra vez de volta à cidade.

\section{COMENTÁRIO}

\section{Fr. II FGE}

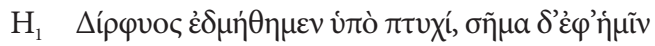

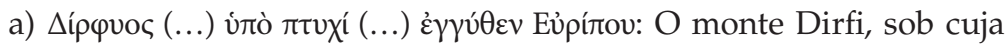
sombra, deu-se a batalha entre calcídios e atenienses é o ponto mais alto da estreita ilha da Eubeia, atingindo $1746 \mathrm{~m}$ de altitude. A sua frente estende-se a planície do rio Lelanto. Page $\mathrm{P}^{74}$ acredita que os calcídios retrocederam até aí para enfrentar os atenienses e é possível que, pressionados pelo ataque desses últimos, tenham recuado ainda mais para o interior, até a encosta escarpada do Dirfi, onde, num último esforço para preservar suas vidas,

${ }^{74}$ Page 1981, 191: "'near the Euripus' presumably means 'in Chalcis'. The battle field is said to have been not there, but 'under the folds of Dirphys'; if this is to be taken literally, the Euboeans must have retreated some distance (perhaps as much as ten miles) to the east or north-east of Chalcis". 
podem ter causado muitas baixas ao contingente de Atenas ${ }^{75}$; a essas baixas na dobra da montanha (írò $\pi \tau v x i ́)$ é que estaria se referindo o epigrama. $\mathrm{O}$ fato de o epigrama se distanciar do local da morte dos guerreiros por men-

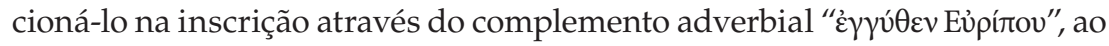
invés do tradicional $\varepsilon \dot{v} \theta \dot{\delta} \delta \varepsilon$ (vel simil.) pode indicar que o epigrama não se tratava de um epitáfio, mas de uma inscrição que acompanhava algum tipo de monumento comemorativo ou cenotáfio na própria cidade de Atenas.

b) $\varepsilon \delta \mu \eta \theta \eta \mu \varepsilon v$ : Essa é forma do aor. ind. pass. da $2^{a}$ pessoa do plural.

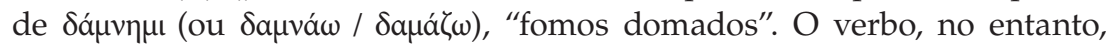
raramente é usado com um agente da passiva pessoal. Na Ilíada ${ }^{76}$ ocorre apenas algumas vezes com esse sentido, p. ex., na ameaça de Tlepolemo a

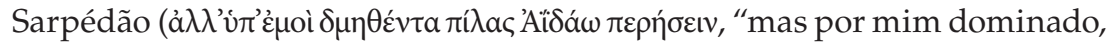
os portões do Hades hás de cruzar"), em outros dois casos, no entanto, os

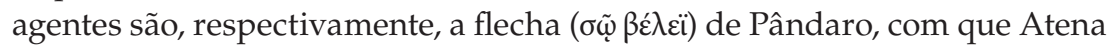
deseja instigá-lo a matar Menelau, ou os presentes com que Agamênão intenta aplacar a fúria de Aquiles. As acepções mais comuns do verbo são (a) para descrever a "doma" da fêmea pelo consorte, sejam esses deuses, homens ou animais ${ }^{77}$ e (b) a vitória final de algum processo ou fenômeno natural (muitas vezes deificado) sobre os homens e seu meio ambiente. No caso de (b) implica, evidentemente, a impotência do homem frente a forças

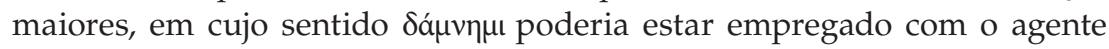
da passiva elíptico, o qual poderíamos identificar com, por exemplo, Aḯdác

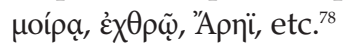

$\mathrm{O}$ que parece ter passado desapercebido pelos comentadores, e que ajuda a reforçar o argumento a favor de uma identificação ateniense para o sujeito do verbo, é a estreita relação entre $\delta a ́ \mu \nu \eta \mu \mathrm{e} \mathrm{a} \mathrm{principal} \mathrm{atividade} \mathrm{dos}$ Calcídios na ilha de Eubeia, a criação e domesticação de cavalos. Não seria surpreendente, portanto, que o poeta escolhesse justamente esse verbo para descrever o único modo pelo qual os atenienses, dessa feita aproximados a garanhões, poderiam ter sido "vencidos" pelos Eubeus, mestres na arte de domar cavalos. De fato, o sentido de "domar" parece ser o mais antigo em

\footnotetext{
${ }^{75}$ A exemplo do que teria ocorrido com os marathonomachai, durante a invasão persa de 490, no monte Agrilice. A planície do rio Lelanto viu muitas batalhas sangrentas, das quais a mais famosa, talvez, tenha sido a Guerra Lelantina (c. séc. vil a.C.) entre Cálcis e Erétria. Cf. o fr. 3W 2 de Arquíloco e o comentário em Corrêa (1998, 165-77).

${ }^{76}$ As passagens são, respectivamente $I l .5 .646,4.99,9.158$.

${ }_{77}$ Cf. " $\delta a ́ \mu-\alpha \rho "$ ", esposa, mulher. Esse uso é muito comum na Teogonia para descrever os inúmeros casamentos celestiais e humanos. Cf. vv. 327, 374, 453, 962, 1000, 1006. O verbo é, assim. especialmente associado a Eros e Afrodite, p. ex., Hes. Scut. 48; Fr. 23a; Fr. 195.48; Hom. Ilíada 14.316.

${ }^{78}$ Donde são exemplos, respectivamente, AG 7.737.2 e IGBulg I² 463(3); SEG 6.567, IG XII.8 92, IG XII.8 600
} 
Grego e pode ser reconstruído quase sem alterações na maioria da línguas indo-europeias a partir de um radical único, ${ }^{*} d e m h_{1}-$, donde o grego $\delta a ́ \mu \nu \eta \mu u$, o latim dōmo (daí o "dom-ar", em português) o hitita dam-aszi, o sânscrito dām-aya-ti e, a partir do germânico, o alemão zähmen (>d(z)a(e)m-) e o inglês tame (>dam- $)^{\prime \prime},{ }^{79}$ todas essas, palavras estreitamente associadas à domesticação do cavalo.

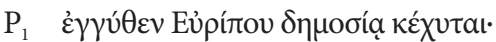

$\Sigma \tilde{\eta} \mu \alpha$, enquanto índex, é qualquer sinal que se coloque para marcar alguma coisa.$^{80} \mathrm{Na}$ acepção de monumento funerário, refere-se, originalmente ao monte de terra (moimento, túmulo) erguido para marcar o local de inumação do(s) morto(s). Esses montes de terra, frequentemente menciona-

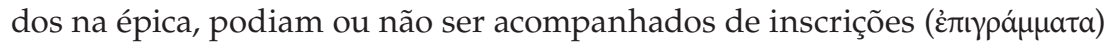
e, quando assim acontecia, aquelas eram, normalmente gravadas sobre es-

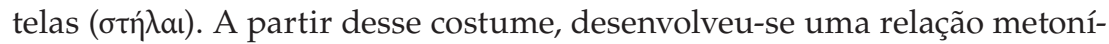

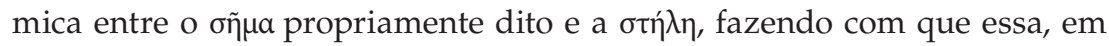

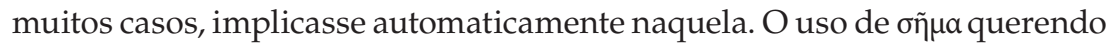
significar "outeiro funéreo" aparece primeiramente em uma passagem na

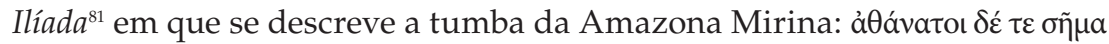

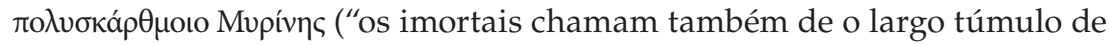
Mirine").

A construção de um oñua acompanhado de alguma espécie de inscrição, no entanto, está implícita no juramento prestado por Heitor ao preparar-se para o combate com Ajax filho de Télamon, ${ }^{82}$ por meio do qual ele revela sua preocupação com o destino de seu corpo, caso venha a morrer em combate, e certifica-se de que, vença quem vencer, este conceda ao outro a honra ( $\gamma \varepsilon ́ p a \varsigma)$ dos ritos funéreo (vékva) adequados: a cremação, no caso dele

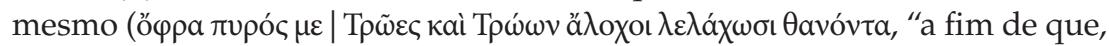
morto, os troianos e suas esposas me entreguem ao fogo") ou a inumação,

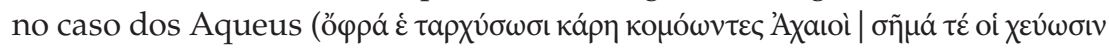

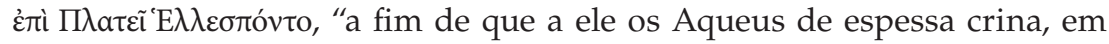

${ }^{79}$ Mallory $(2006,136)$, entre outros, acreditam que o verbo esteja intimamente associado à doma do cavalo pelos indo-europeus.

${ }^{80}$ Para uma discussão mais detalhada desse substantive, cf. Frame 1978 e, sobretudo, Nagy 1990.

${ }^{81}$ Onde encontramos 26 instâncias do substantivo, das quais 12 têm o significado de "lápide

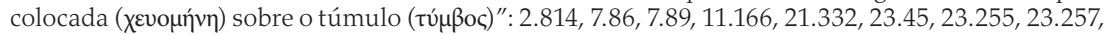
23.331, 24.16, 24.416, 24.801. Na Odisseia o uso é semelhante, com 13 ocorrências, das quais apenas três, no entanto, têm o sentido aludido: 1.291, 2.222, 11.75, um "sinal" que Elpenor pede a

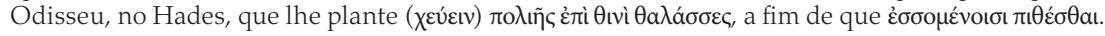

${ }^{82}$ Il. 7.67-91. 
procissão, moimento ajuntem a planície do Mar Grego"). O objetivo desse

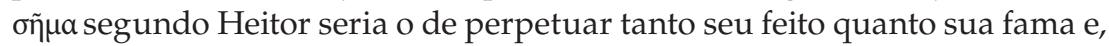
assim, constitui-se igualmente num $\mu \nu \tilde{\eta} \mu \alpha$, ou monumento:

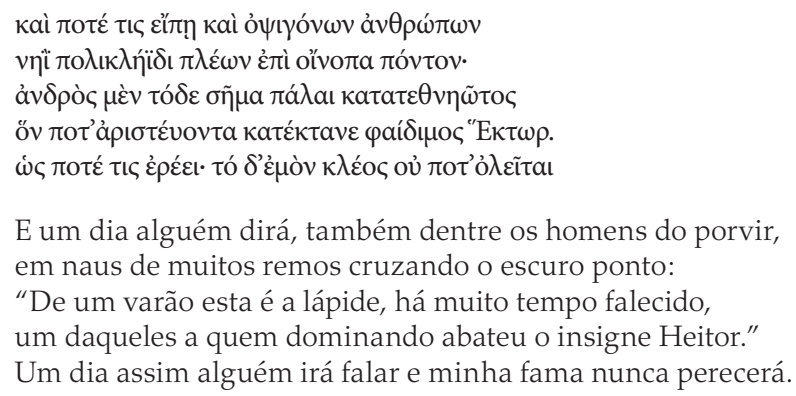

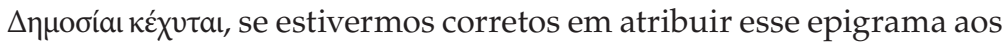
atenienses, só pode querer significar "às expensas do povo", i.e., financiado pelo novo governo popular instituído recentemente por Clístenes.

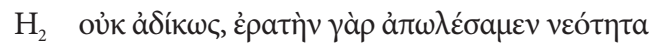

Tanto Diehl quanto Peek não acreditam que o segundo dístico pudesse fazer parte da inscrição, ${ }^{83}$ rejeitando-o como uma adição tardia, no que lhes segue Wilhelm. ${ }^{84}$ Page, embora admitindo o fato de que no vi século poucos epigramas excediam duas linhas em qualquer metro, ${ }^{85}$ discorda. Segundo ele, em vista de novas evidências arqueológicas de inscrições do mesmo período e com mais de duas linhas, a objeção levantada por aqueles pesquisadores perde muito sua força. ${ }^{86}$

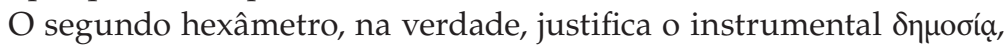
um termo novo e surpreendente, jamais atestado em inscrições anteriores. Talvez por esse motivo o poeta, ou quem comissionou a inscrição, tenha sentido a necessidade de, por um lado, justificar os gastos com um monumento público em honra dos mortos e, por outro, de salientar o cuidado dos concidadãos com aqueles que ofereceram suas vidas em sacrifício pelo bem

${ }^{83}$ Apud Page 1981.

${ }^{84}$ Wilhelm 1899 (Jahresh. der Oest. Arch. Inst. Wien 2:244), apud Page 1981.

${ }^{85}$ Page 1975, 9: "3-4 postmodo additos esse coni. Wilhelm, perperam opinor". Ainda Page 1981, 190: "and [sc. as inscrições do séc. v] generally state the facts (as in the first couplet) without comment (as in the second)"

${ }^{86}$ Page $(1981,190)$ cita, como exemplo, Peek 1226, e conclui: "In the light of this example the objective case against the second couplet must be judged inconclusive; the veredict then depends on personal impressions, and it would be hard to give a good reason why these should be unfavourable." 
comum. Ao ler a inscrição, precisamos nos lembrar de que a mesma pode ter sido destinada a permanecer numa terra estrangeira ou, no mínimo, longe da pátria dos mortos e que, assim, estaria sujeita a ser lida por diferentes pessoas, gregos e bárbaros, viajantes em sua grande maioria, já que Cálcis sempre fora um entreposto de trocas, devido ao porto da cidade que se situava numa entrada estratégica para o golfo da Eubeia. Desse ponto de vista, seria importante "publicizar" os valores de virilidade ateniense, de um lado, e do cuidado da pátria para com seu cidadãos, de outro.

No entanto, ao invés da cidade, quem fala são próprios mortos, como seria de se esperar de uma inscrição funerária, mas há um subtexto aí presente. Se entendermos o conceito de $\delta$ íkn $\eta^{87}$ como um valor distributivo e sobretudo pragmático, baseado num conjunto de regas estabelecidas coletivamente, e que define o que cabe a cada um de acordo com as ações indi-

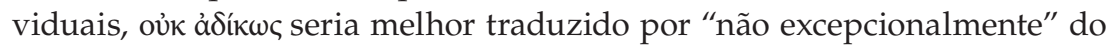
que por "não injustamente", já que aqui o sentido prático de dar a alguém o que lhe é devido como quinhão é bastante claro: há uma troca de x por $\mathrm{Y}$, independente do juízo de valor que se possa fazer sobre essa troca ou sobre aqueles que a operam, como poderíamos ser levados a crer a partir do nosso próprio conceito de "justiça". A troca aludida, obviamente, diz respeito àquela da morte pela honra (ou lembrança): dentro do contexto da isonomia clisteniana e da proibição de memoriais particulares para os mortos, esse era o único caminho de excelência pessoal a que um ateniense

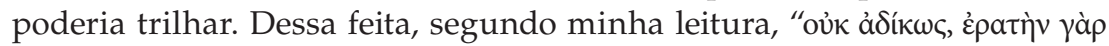
ả $\pi \omega \lambda \varepsilon ́ \sigma \alpha \mu \varepsilon v \nu \varepsilon o ́ t \eta \tau \alpha^{\prime \prime}$ preservaria um sentido mais próximo do original se traduzido de uma maneira um pouco mais prosaica: "não excepcionalmente [recebemos essa honraria, sc. tò oñua] porque [para tê-la] arruinamos nossa amável juventude".

Sobre o vocabulário, seria importante notar que o verbo ảmó $\lambda \lambda \nu \mu \mathrm{u}$ (cf. lat. ab-oleo, de uma raiz indo-erupoeia $\left.{ }^{*} h_{3} e l h_{1}\right)$, cujo significado principal é o de "destruir completamente, sem deixar vestígios", pode, quando usado transitivamente, ter a acepção de "esgotar" ou, mais especialmente, "perder, acabar, arruinar, gastar precocemente" ${ }^{88}$ Segundo Derderian ${ }^{89}$ :

Ao passo que a maioria dos epigramas arcaicos usam $\theta$ aveĩv para marcar uma morte [natural], os epigramas claramente associados com guerreiros usam ö $\lambda \varepsilon \sigma \theta a \mathrm{l}$, tanto em suas formas transitivas quanto intransitivas. A maioria dos usos da forma transitiva

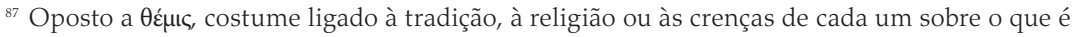
certo ou errado.

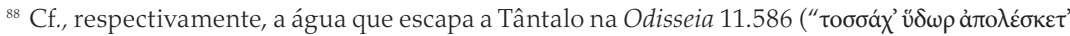

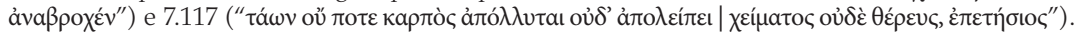

${ }^{89}$ Derderian 2001, 97.
} 
de ö $\lambda \varepsilon \sigma \theta a ı$ atribui a morte a Ares (CEG 27.2, 145.1) ou mesmo ao próprio guerreiro, emprestando à guerra ou ao próprio guerreiro um novo papel ativo na destruição e na resultante memorialização da juventude do guerreiro.

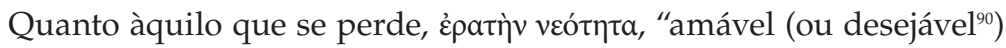
juventude", ela aqui é colocada desde um ponto de vista heroico, já que a juventude só pode ser desejável (e, de certa forma, invejável), na medida em que ela capacita aqueles que a possuem a participar dos combates, contrapondo-se, automaticamente, à velhice ( $\gamma \tilde{\eta} \rho a \varsigma)$, classificada, dentro desse sistema de valores guerreiro, como aiox $\rho^{a} .{ }^{91}$

Page avalia todo o pentâmetro como típico entre os epigramas de

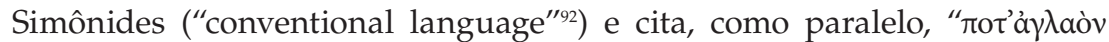

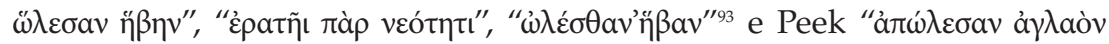

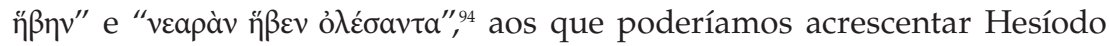

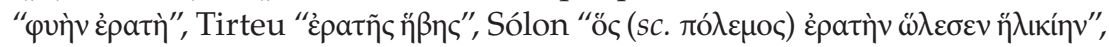

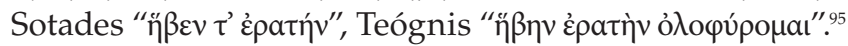

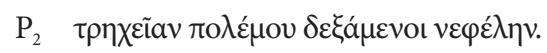

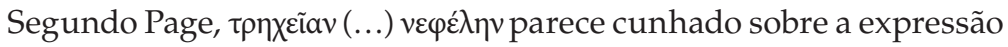

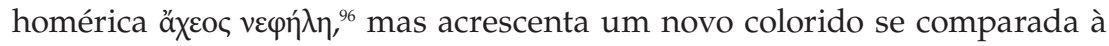

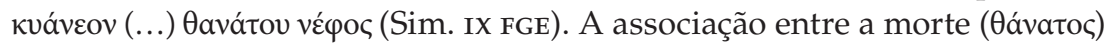
e nuvem ou neblina que turva a vista (variavelmente descrita como negra, áspera ou dorida) pertence ao imaginário indo-europeu. Os próprios radi-

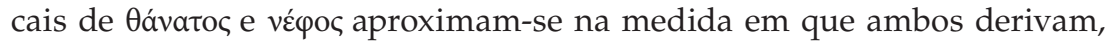
no caso daquele, ou convergem, no caso deste, para a ideia de "obscurecer,

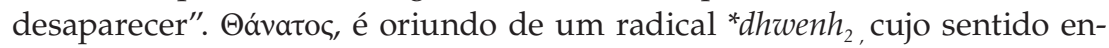
globava as noções de "cobrir, sobrepor-se, esconder, escurecer por privar de luz", donde o sânscrito tirou $d^{h} v \bar{a} n t a\left(<d^{h} v a n\right)$, "coberto, escuro, velado";

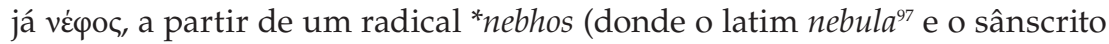
nabhas), fez surgir, no inglês arcaico o adjetivo nifol, com o significado de "escuro".

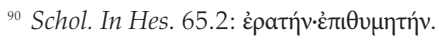

${ }^{91}$ Cf. Tirteu, fr. $10 \mathrm{~W}^{2}$. Sobre a associação entre a guerra e a perda da juventude pelo bem comum. Cf. a excelente discussão de Derderian 2001, 97 et seq.

${ }_{92}$ Page 1981, 191, 3-4 et n.91.

${ }_{93}$ Respectivamente, Sim. 46, 70 e 49 FGE.

${ }^{94}$ Peek 18.1, 305.3/1226.3

95 Teógnis 1131.

${ }^{96}$ Ilíada 17.591, 18.22.

${ }_{97}$ Mas não nūbess, advindo de outro radical *sneudh-. 
Outra ideia imediatamente sugerida pela associação, não mais entre

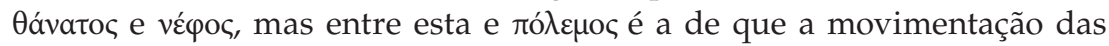
tropas deveria levantar a poeira do chão e, assim, cobrir os soldados numa nuvem escura de areia fina. Areia e pó que, entrando no trato respiratório, poderiam causar a sensação sugerida pelo adjetivo $\tau \rho \eta \chi \varepsilon \tilde{a}$, que, talvez por

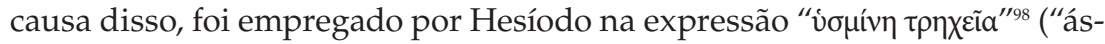

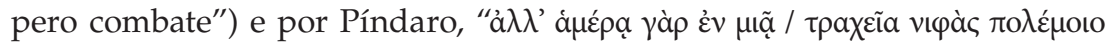

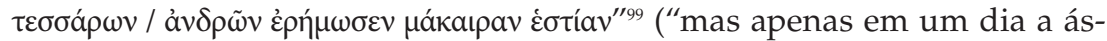
pera nuvem da morte de quatro varões os privou da bem-aventurada lareira"). Entre os fragmentos épicos de Eufório, ademais, lemos " $\Delta i ́ p \varphi v v$ àvà

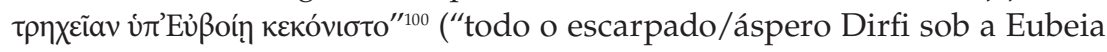
foi coberto de poeira"), o que pode sugerir um terreno propenso a levantar nuvens de poeira. Finalmente, тpaxúc também pode normalmente usado para qualificar lugares escarpados. Por exemplo, como epíteto de Ítaca, Odisseia 9.17 e 10.417 e também para o Quersoneso, Herod. 4.99. Dessa forma, é impossível decidir entre um sentido metafórico ou literal (ou ambos) para a expressão em questão, mas é possível dizer que, dado o terreno da batalha, ela parece bastante apropriada para descrever a ocasião do choque entre os dois exércitos.

\section{Fr. III FGE}

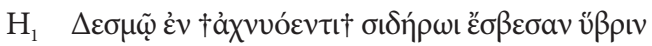

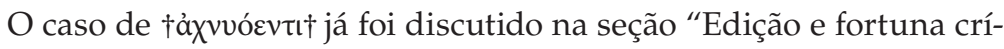
tica", quando falávamos do estabelecimento do texto do epigrama. Aqui gostaríamos de chamar a atenção, para a semelhança entre esse hexâmetro

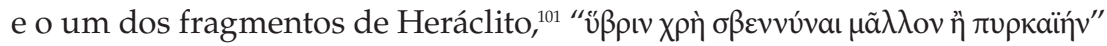
("deve-se apagar o hýbris mais do que a lareira"), uma variação, segundo

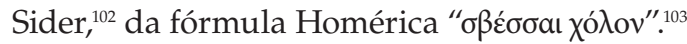

\footnotetext{
${ }_{98}$ Hes., Scutum 119.

${ }^{99}$ I. 4.16-18.

${ }^{100}$ Eufório, fr. 73.1, tradução hipotética, devido ao estado fragmentário do trecho.

${ }^{101}$ Herac., fr. 43.1.

102 Sider 2007, 126 n.41.

${ }^{103}$ Ilíada 9.678.
} 


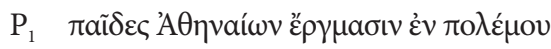

Page nos diz que a colocação dativo $+\dot{\varepsilon} v+$ genitivo adjetival, como

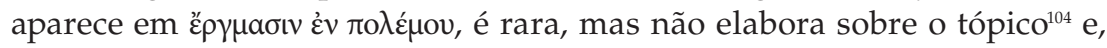
como o LSJ lista apenas esse verso de Simônides como exemplo, há razões para se acreditar que estejamos frente a um hapax. Schneidewin não comenta o uso. Bergk nota que em um dos manuscritos de Heródoto temos

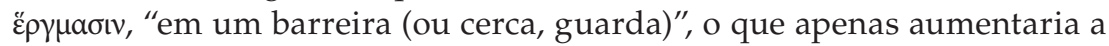

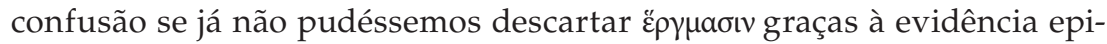

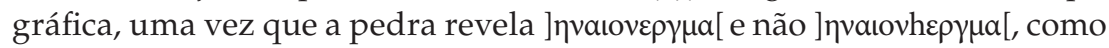
seria de se esperar, fosse o épsilon aspirado. O codex conhecido como An-

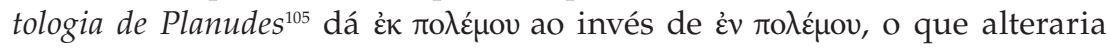

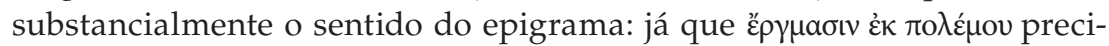
saria ser construído com $\varepsilon ̋ \varepsilon \sigma \alpha v$, e não com $\delta a \mu a ́ \zeta \omega$, "por meio dos trabalhos oriundos da guerra, dedicaram um décimo ( $s c$. , do dinheiro obtido com o resgate dos cativos) (...) [para erigir] essas [éguas]", o que, como se vê, gera uma sintaxe assaz convoluta e rompe com a unidade semântica mais

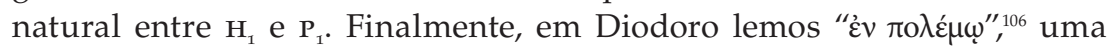
leitura que, embora possível, parece ser uma simplificação pedestre da versão poética e, provavelmente, deve ter se originado por meio de hipercorreção do original. Uma vez que a pedra está danificada neste ponto, não é possível decidir a questão.

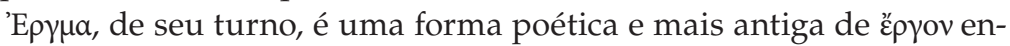
contrada pela primeira vez em Hesíodo, ${ }^{107}$ e, depois, em Teógnis, ${ }^{108}$ Sólon, ${ }^{109}$ Píndaro $^{110}$ e Ésquilo, ${ }^{111}$ entre outros. Nunca, todavia, ele aparece junto de

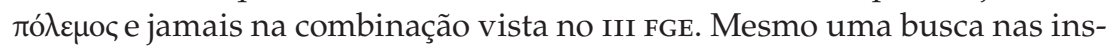
crições epigráficas do banco de dados do PHI não revela nada parecido, além de, também lá, ép $\gamma \mu a \sigma v v$ aparecer em apenas cinco inscrições, ${ }^{112}$ dentre as quais a do epigrama em questão.

${ }^{104}$ O exemplo fornecido por Petrovic (2007, 216 n.24) ignora o fato de que é a colocação (i.e., a ordem dos elementos na frase) que é atípica, e não a sintaxe.

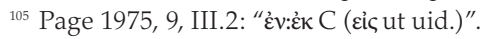

${ }^{106}$ Cf. nota 34.

${ }^{107}$ Hes. Teog. 823; Erga 801.

${ }^{108}$ Teógnis, $29 \mathrm{~W}^{2}$.

${ }^{109}$ Fr. $4.11 \mathrm{~W}^{2}$.

${ }^{110}$ Pind. N. 4.6.

${ }^{111}$ Respectivamente, Sete contra Tebas 555; Eumênides 501.

${ }_{112}$ Todas tardias. IG II ${ }^{2}$ 5768, IV sec. a.C.; III FGE (IG I³ 501; Raubitschek, DAA 168 e 173); Aphrodisias 732, vi séc. d.C.; Ephesos 3083, período romano; IK Laodikeia am Lykos 11, v/ıv séc. a.C.; SEG 24:1243, não datada, porém tardia, período romano talvez. 


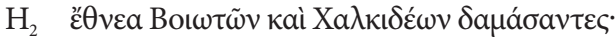

"EӨvea aqui é certamente usado com o sentido (pré-)homérico de "horda, rebanho, multidão" especialmente de animais, pássaros e insetos

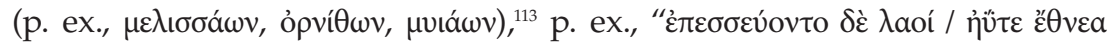

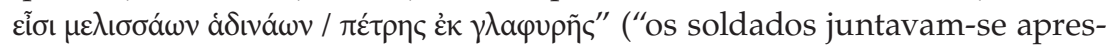
sados: como um grosso enxame de abelhas sai / de uma oca pedra") $)^{114}$;

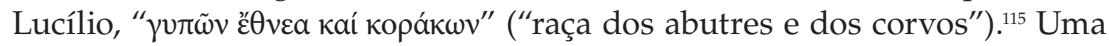
vez que $\delta a \mu a ́ \sigma a v \tau \varepsilon \varsigma$ remete-nos à principal atividade dos calcídios e eubeus (e também a $\mathrm{H}_{1}$ do II FGE), domar cavalos e, igualmente, por esses serem agrupados em rebanhos pelos campos, pode haver uma fina ironia nesse verso, que retrata os domadores como domados, fugindo em bandos para o abrigo das colinas do Dirfi. ${ }^{116}$ Note, finalmente, a clara oposição entre os "filhos dos Atenienses" e "os bandos de beócios e calcídios" no início de $\mathrm{P}_{1}$ e $\mathrm{H}_{2}: \pi \alpha i \tilde{\delta} \varepsilon \varsigma \mathrm{x} \varepsilon \ddot{\varepsilon} \theta v \varepsilon \alpha$.

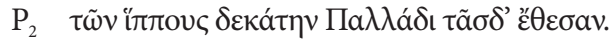

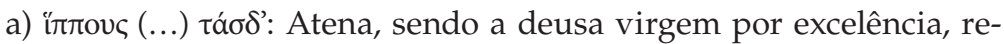

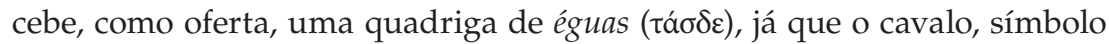
de força sexual e atributo de Posidão (com quem, aliás, ela competiu pelo padroado da cidade), seria extremamente inadequado. A quadriga obviamente deve representar a carruagem da deusa $N i ́ k \bar{e}$, ou Vitória, e é mesmo provável que a tivesse como auriga. ${ }^{117}$ A metáfora da "carruagem da Vitória" seria facilmente apreendida pelos atenienses e não é estranha aos que estudam a linguagem dos epinícios, onde o tropo aparece pela primeira vez no

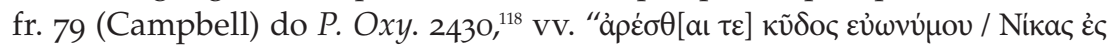

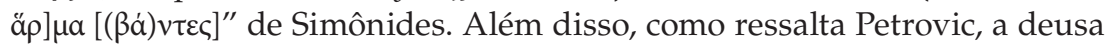
está associada à doma do cavalo por meio da invenção do freio e era nessa

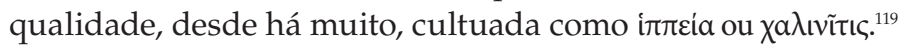

b) $\varepsilon$ $\theta \varepsilon \sigma \alpha v$ : Schneidewin, considerando essa forma uma corruptela, corrige-a para ảvé $\theta \varepsilon v$, numa analogia com o fr. XIII FGE. ${ }^{120}$ Bergk a restitui

\footnotetext{
${ }^{113}$ Talvez a partir de um radical indo-europeu *suedh-nos, que, segundo Frisk, IEED, 1448-9, significaria "Schar, Haufe, Schwarm (von Menschen und Tieren; Hom., Pi., A.)".

${ }^{114}$ Ilíada 2.87; cf. tb. 2.459 e 469.

${ }^{115}$ Lucílio, AG 11.191.6.

${ }_{116}$ Petrovic 2007, 216.

${ }^{117}$ Cf. Baumbach 2010, 124.

${ }^{118}$ Ed. et suppl. Lobel, P. Oxy. vol. 25.

${ }^{119}$ Petrovic 2007, 216. Cf. ainda Paus. 1.30.4; 1.31.6.

${ }^{120}$ Schneidewin 1865: "Vulgo عُ $\theta \varepsilon \sigma \alpha v$ : codex ảvé $\theta \varepsilon \sigma \alpha v$. Hinc ảvé $\theta \varepsilon v$ restitui, de qua forma v. Epigr. 117,2".
} 
para a forma atual que, segundo Page teria o mesmo significado de àvatí $\eta \mu$, ou seja, "dedicar e, como exemplo que suporte sua tese, cita o fr. Sim. xxIV

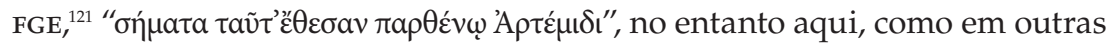
passagens, है $\theta \varepsilon \sigma a v$ pode simplesmente significar "erigiu, construiu, fez", já que, pelo caráter do monumento, seria mais do que óbvio a qualquer um que o contemplasse que se tratava de uma oferenda votiva.

\section{REFERÊNCIAS}

Baumbach, M., A. Petrovic, e I. Petrovic. 2010. Archaic and Classical Greek Epigram. Cambridge: Cambridge University Press.

Beekes, R.S.P., and L. Van Beek, eds. 2009. Etymological Dictionary of Greek. Leiden/ Boston: Brill Academic Publishers. (Leiden Indo-European Etymological Dictionary Series v. 10, 1-2).

Bergk, T., ed. 1878-1882. Poetae Lyrici Graeci. Leipzig. 3 vols. (Vol. 3, 1843).

Boas, M., ed. 1905. De Epigrammatis Simonideis. Pars prior: commentatio critica de epigrammatum traditione. Groeningen: J. B. Wolters.

Brose, Robert de. 2007. "Os fragmentos atenienses de Simônides: um estudo das fontes epigráficas anteriores a 480 a.C." Dissertação de Mestrado. Universidade de São Paulo.

Brose, Robert de. 2008. "Os epigramas IG3 503 e 504: uma reavaliação." Revista do Museu de Arqueologia e Etnologia 18:239-57.

Brose, Robert de. 2011. "Epigramas Bélicos e a elegia à Batalha de Platéias." \{n.t. Revista Literária em Tradução 1:302. Disponível em: <http://www.notadotradutor. com>.

Corrêa, Paula C. 1998. Armas e varões: a guerra na lírica de Arquíloco. São Paulo: Fundação Editora da UNESP.

Derderian, K. 2001. Leaving words to remember: Greek mourning and the advent of literacy. Leiden: Brill. (Mnemosyne, Bibliotheca Classica Batava, v. 209).

Frame, D. 1978. The Myth of Return in Early Greek Epic. New Haven: Yale University Press. (Disponível em http://chs.harvard.edu/CHS/article/display/4317, acessado em janeiro de 2011).

Friedländer, P., and H. B. Hoffleit, eds. 1948. Epigrammata: Greek inscriptions in verse from the beginnings to the Persian Wars: Univ. of California Press.

Hauvette-Besnault, A. 1896. De l'authenticité des épigrammes de Simonide. Paris: F. Alcan. Hecker, A. 1843. Commentatio Critica de Anthologia Graeca. Leiden: S. et J. Luchtmans.

Hicks, E. L., and G. F. Hill. 1901. A Manual of Greek Historical Inscriptions. Cambridge: Cambridge University Press.

Jacoby, F. 1945. "Some Athenian Epigrams from the Persian Wars." Hesperia 14(3):54.

Kaibel, G., ed. 1878. Epigrammata Graeca ex Lapidibus Conlecta. Berlin: Reimer.

${ }^{121}$ Ver texto e tradução em Brose 2011.

Let. Cláss., São Paulo, v. 17, n. 2, p.3-30, 2013 
Mallory, J.P., and D.Q. Adams. 2006. The Oxford Introduction to Proto-Indo-European and the Proto-Indo-European World. Oxford Linguistics. Oxford: Oxford University Press.

Molyneux, J.H. 1992. Simonides: A Historical Study. Illinois: Bolchazy-Carducci Publishers.

Nagy, G. 1990. "Sêma and Nóésis: The Hero's Tomb and the 'Reading' of Symbols in Homer and Hesiod." Greek mythology and poetics. Ithaca: Cornell University Press. (Disponível em http://chs.harvard.edu/CHS/article/display/1289, acessado em janeiro de 2011).

Page, D. L., ed. 1975. Epigramata Graeca. Oxford: Oxford University Press. (Oxford Classical Texts.)

Page, D.L. 1981. Further Greek Epigrams. Cambridge: Cambridge University Press.

Paton, W.R., ed. 1979. The Greek anthology. 5 vols. Massachussets: Harvard University Press. (Loeb Classical Library).

Petrovic, A., ed. 2007. Kommentar Zu Den Simonideischen Versinschriften. Leiden: Brill. (Mnemosyne: Bibliotheca Classica Batava, v. 282).

Schneidewin, F. W., ed. 1835. Simonidis Cei Carminum Reliquiae. F. Vieweg.

Segal, C. 1976. "Bacchylides Reconsidered: Epithets and the Dynamics of Lyric Narrative." QUCC (22):99-130.

Sider, D. 2007. "Sylloge Simonidea." In Brill's Companion to Hellenistic Epigram, edited by P. Bing e J.S. Bruss, 113-30. Leiden/Boston: Brill.

Turner, E. G. 1962. "Simonides and the epigram on the fetters of the Chalcidians in a new papyrus." PCA 59:21-2.

West, S. 1985. “Herodotus' Epigraphical Interests." The Classical Quarterly 35(2):278-305.

\section{*}

Title. The demos goes to war: translation and commentary of fr. II and III FGE attributed to Simonides of Ceos.

Abstract. In the present paper, I shall translate and present a commentary of fr. II and III FGE, attributed to Simonides of Ceos. Based on the literary analysis, the historical context and textual evidence, I shall argue, together with previous scholars, that both epigrams refer to the same event, namely, the Battle of Chalcis (c. 507/6 BC). In this scenario, I shall propose that fr. II FGE refers to the Athenian fallen in combat, and that the inscription was probably part of a monument placed in situ or in a mnema at the city of Athens. On the other hand, III FGE, which presents a thematic unity with the previous epigram, may have been part of a monument commemorating the victory of the Athenians over the Boeotians in that same battle.

Keywords. Simonides of Ceos; epigram; II FGE; III FGE. 